\title{
Focused Electron Beam and Elemental Mapping of Palm-top EPMA (Scanning) Equipped with CL Spectrometer (Projection)
}

\author{
Susumu Imashuku, Naoto Fuyuno, Akira Imanishi, Kohei Hanasaki, Kengo Ohira and Jun Kawai \\ Department of Materials Science and Engineering, Kyoto University, Kyoto, Japan
}

We realized an electron probe microanalyzer (EPMA) and X-ray tube with a palm-top size chamber including the electron source and the sample stage using pyroelectric crystal as the electron source $[1,2]$. Electrons in the palm-top EPMA and X-ray tube were bombarded on the sample stage and the stainless steel chamber because a rectangular $\mathrm{LiTaO}_{3}$ crystal was used. Thus, it is difficult to measure $\mathrm{Cr}, \mathrm{Fe}$ and $\mathrm{Ni}$ with the palm-top EPMA. In the present study, we tried to focus the electron beam of the palm-top EPMA on samples by standing a metal wire on the pyroelectric crystal in order to prevent the production of an electric field at the wall of the chamber. We also performed elemental mapping by cathode luminescence $(\mathrm{CL})$ using the pyroelectric crystal and a small camera.

A schematic view of the palm-top EPMA is shown in Fig. 1 (a). $+z$ plane of a single crystal of $\mathrm{LiTaO}_{3}$ with $3 \mathrm{~mm} \times 3 \mathrm{~mm}$ in $\mathrm{x}-\mathrm{y}$ plane and $5 \mathrm{~mm}$ in z-axis was attached on a Peltier device with silver paste. A gold wire was tightened into a hole in the silver stage with a screw. The silver stage with the gold wire was attached to the $\mathrm{LiTaO}_{3}$ crystal with silver paste. As for CL spectrometer, a small camera was introduced into the sample chamber with $\mathrm{T}$ shape ISO quick release coupling and detachable vacuum joints. Measurements were carried out during cooling the $\mathrm{LiTaO}_{3}$ crystal by applying -3 volt $\mathrm{DC}$ to the Peltier device. Pressure of the sample chamber was set to $2 \mathrm{~Pa}$ during the measurements.

Figure 1 (b) shows EDX spectra of titanium plate with and without the gold wire on the $\mathrm{LiTaO}_{3}$ crystal. Although the gold wire was attached to the $\mathrm{LiTaO}_{3}$ crystal, $\mathrm{Cr}, \mathrm{Fe}$, and $\mathrm{Ni} \mathrm{K}$ lines from the stainless steel were detected in addition to $\mathrm{Ca}$ and $\mathrm{Ti} \mathrm{K}$ lines. This is because an electric field was produced between the surface of the silver stage and area including the sample stage and the wall of the stainless steel ISO quick release coupling as shown in Fig. 2 (a). On the other hand, Ca and Ti K lines were only detected when we covered the silver stage holding the gold wire with high-vacuum grease. This result indicates that an electric field was produced between the tip of the gold wire and the sample stage and that electrons were focused on the sample as shown in Fig. 2 (b). The spot size of the electron beam was calculated to be $100 \mu \mathrm{m}$ by the distribution of the brightness of the illuminated region in Fig. 2 (b) (Fig. 2 (c)).

We then carried out elemental mapping by applying CL phenomena of rare earth element. Fig. 3 shows photo of $\mathrm{TbF}_{3}$ and $\mathrm{GdF}_{3}$ powders with the pyroelectric $\mathrm{CL}$ spectrometer. It was observed that $\mathrm{TbF}_{3}$ and $\mathrm{GdF}_{3}$ glowed green and red, respectively. The illuminated area of $\mathrm{GdF}_{3}$ was smaller than that of $\mathrm{TbF}_{3}$ because the luminescence intensity of $\mathrm{GdF}_{3}$ was 20 times lower than that of $\mathrm{TbF}_{3}$. From this result, we succeeded in carrying out elemental mapping of rare earth elements using the pyroelectric CL spectrometer. 
References:

[1] S Imashuku, A Imanishi and J Kawai, Anal. Chem. 83 (2011), p. 8363.

[2] S Imashuku and J Kawai, Rev. Sci. Instrum. 83 (2012) p. 016106.
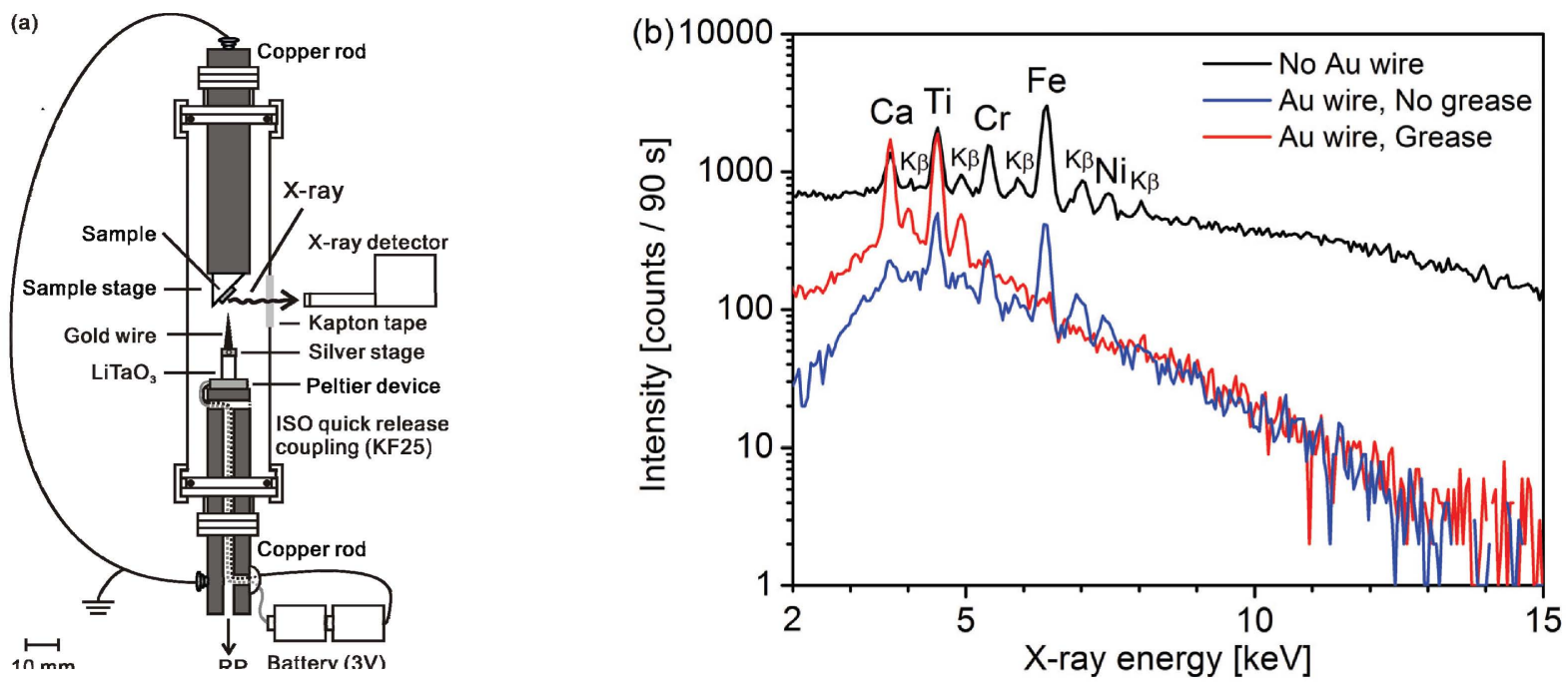

Figure 1. (a) Schematic views of palm-top EPMA. (b) EDX spectra of the mixture of $\mathrm{CaF}_{2}$ and $\mathrm{TiO}_{2}$ powders with and without the gold wire on the $\mathrm{LiTaO}_{3}$ crystal.
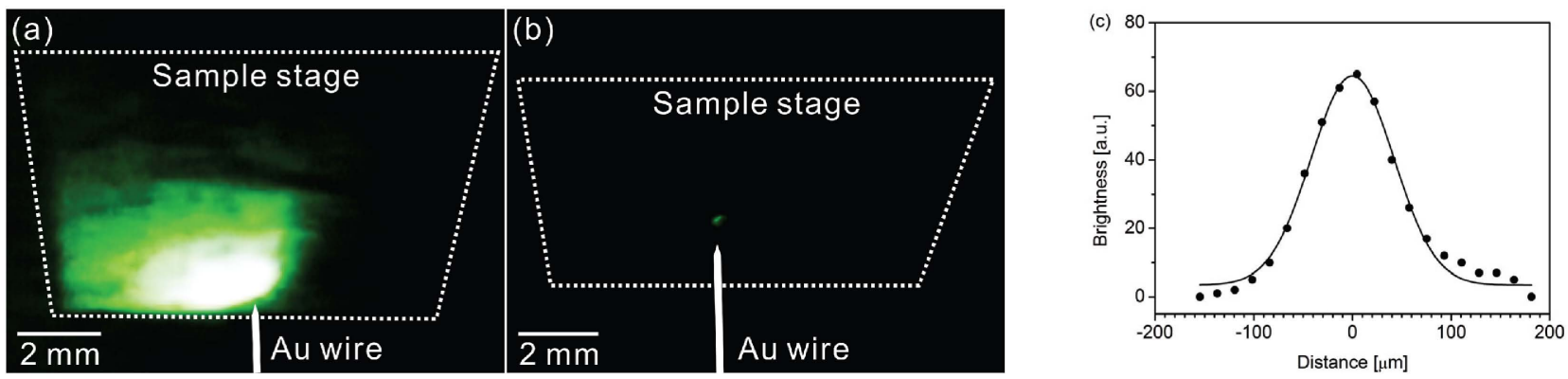

Figure 2. Photos of fluorescent screens during the bombardment of electrons. (a) Gold wire on the $\mathrm{LiTaO}_{3}$ crystal without covering the silver stage with high-vacuum grease. (b) Gold wire on the $\mathrm{LiTaO}_{3}$ crystal and the silver stage covered with high-vacuum grease. (c) Distribution of brightness of the illuminated area in Fig. 2 (b)

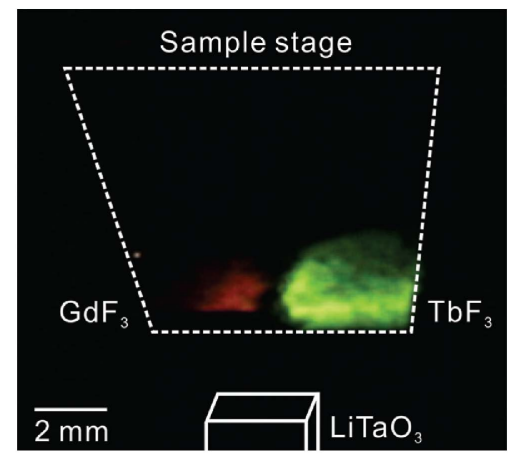

Figure 3. Photos of $\mathrm{TbF}_{3}$ and $\mathrm{GdF}_{3}$ powders during bombarding electrons with the pyroelectric CL spectrometer. 